\title{
CARACTERIZACIÓN BIOQUÍMICA DE EXTRACTOS ACUOSOS DE Ulomoides dermestoides (COLEOPTERA, TENEBRIONIDAE): EXPLORACIÓN DE LA INHIBICIÓN DUAL DE LA LIPOXIGENASA (15- LOX) Y CICLOOXIGENASAS (COX-1 Y COX-2)
}

\author{
Dary Luz Mendoza Meza ${ }^{1}$ \\ Karen Sánchez Catalán ${ }^{2}$ \\ Stephanie Saavedra Ahumada ${ }^{3}$
}

\section{RESUMEN}

Ulomoides dermestoides es usado en medicina tradicional oriental para aliviar enfermedades inflamatorias y como afrodisíaco. En Colombia, comunidades campesinas lo consumen para el tratamiento del asma. El propósito de este estudio fue obtener extractos acuosos del cuerpo entero de $U$. dermestoides y explorar su potencial para inhibir enzimas involucradas en la biosíntesis de reguladores de la inflamación, la 15-lipoxigenasa (15-LOX) y las ciclooxigenasas COX-1 y COX-2 (COXs).

Los extractos se obtuvieron con tampón salino fosfato $0,01 \mathrm{M}$ (PBS) y bicarbonato de amonio $0,1 \mathrm{M}\left(\mathrm{NH}_{4} \mathrm{HCO}_{3}\right)$, en presencia de un detergente (Tween-20 o Dodecilsulfato sódico, SDS). Posteriormente se determinó el contenido de proteínas totales solubles, el perfil electroforético y las actividades enzimáticas a 19 hidrolasas. Las inhibiciones 15-LOX y COXs se midieron por método colorimétrico y por inmunoensayo enzimático, respectivamente.
El rendimiento más alto de proteínas se obtuvo con el tampón PBS/SDS (1,603 \%p/p). Este extracto mostró 13 bandas electroforéticas mayoritarias, con tamaños entre 8,8 y 151,2 $\mathrm{kDa}$; también, se demostraron actividades enzimáticafosfosfohidrolasas, peptidasas, esterasas, $\beta$-glucoronidasa, $\alpha$-glucosidasa, $\mathrm{N}$-acetil- $\beta$-glucosaminidasa y $\alpha$-manosidasa. Todos los extractos mostraron actividad inhibitoria dual 15-LOX y COXs. Las inhibiciones 15-LOX y COX-1 más altas se obtuvieron con el extracto obtenido con PBS/SDS (15-LOX: 62,8 $\pm 2,0 \%$; COX-1: $88,5 \pm 3,9 \%$ ). Adicionalmente, un análisis de regresión lineal simple mostró que no hay asociación entre la concentración de proteínas y la inhibición 15-LOX (valor $p=0,493$ ), este resultado sugiere que la actividad antilipooxigenasa podría ser debido a compuestos no proteicos.

Palabras clave: Ulomoides dermestoides, inflamación, 15-lipoxigenasa, ciclooxigenasas.

\footnotetext{
${ }^{1}$ Magíster en Ciencias Bioquímicas. Grupo de Investigación en Productos Naturales y Bioquímica de Macromoléculas. Programa de Química, Facultad de Ciencias Básicas. Universidad del Atlántico. E-mail: darymendoza@mail.uniatlantico. edu.co

2 Pregrado en Química. Grupo de Investigación en Productos Naturales y Bioquímica de Macromoléculas. Programa de Química, Facultad de Ciencias Básicas. Universidad del Atlántico. E-mail: karensanchezcatalan@hotmail.com

${ }_{3}$ Pregrado en Química. Grupo de Investigación en Productos Naturales y Bioquímica de Macromoléculas. Programa de Química, Facultad de Ciencias Básicas. Universidad del Atlántico. E-mail: saavedra.stephanie@gmail.com
} 


\section{BIOCHEMICAL CHARACTERIZATION OF Ulomoides dermestoides (COLEOPTERA, TENEBRIONIDAE) AQUEOUS EXTRACTS: EXPLORATION OF DUAL INHIBITION OF LIPOXYGENASE (15-LOX) AND CYCLOOXYGENASE (COX-1 AND COX-2)}

\begin{abstract}
Ulomoides dermestoides is used in traditional oriental medicine to alleviate inflammatory diseases and as an aphrodisiac. In Colombia, rural communities consume it as treatment for asthma. The purpose of this study was to obtain aqueous extracts of whole body of $U$. dermestoides and explore their potential to inhibit enzymes involved in the biosynthesis of inflammation regulators, 15-lipoxygenase (15LOX) and cyclooxygenases COX-1 and COX-2 (COXs).
\end{abstract}

Extracts were obtained with phosphate buffered saline $0.01 \mathrm{M}$ (PBS) and ammonium bicarbonate

\section{INTRODUCCIÓN}

La inflamación es un proceso multifactorial regulado por la activación coordinada de mediadores pro-inflamatorios y antiinflamatorios (1), en el que están implicados fibroblastos, macrófagos tisulares, células endoteliales, mastocitos y leucocitos $(2,3)$. La inflamación crónica se ha relacionado con la activación prolongada de mediadores proinflamatorios, lo que provoca lesiones en tejidos y disfunción orgánica a largo plazo; estos eventos se han observado en la fisiopatología de enfermedades como la obesidad, asma, artritis,
$0.1 \mathrm{M}$ (NH4HCO3) in the presence of one detergent (Tween-20 or Sodium dodecyl sulfate, SDS). Then, total soluble protein, electrophoretic profile and enzymatic activities at 19 hydrolases were determined. Inhibition of 15-LOX and COXs were measured by colorimetric method and enzymatic immunoassay respectively.

The highest protein yield was obtained with PBS/SDS buffer (1.603 \% p/p). This extract showed 13 major electrophoretic bands with molecular weights between 8.8 and $151.2 \mathrm{kDa}$; also, enzymatic phosphohydrolase, peptidase, esterase, $\beta$-glucuronidase, $\alpha$-glucosidase, $\mathrm{N}$-acetyl- $\beta$-glucosaminidase and $\alpha$-mannosidase activities were proven. All extracts showed dual inhibitory activity for 15-LOX and COXs. The higher inhibitions for 15-LOX and COX-1 were obtained with PBS/SDS extract (15-LOX: $62.8 \pm 2 \%$; COX-1: $88.5 \pm 3.9 \%$ ). Additionally, a simple linear regression analysis showed nonrelationship between the protein concentration and 15-LOX inhibition ( $p$ value $=0.493$ ). This result suggests that anti-lipoxygenase activity could be due to non-protein compounds.

Key words: Ulomoides dermestoides, inflammation, 15-lipoxygenase, cyclooxygenase

enfermedad cardiovascular, diabetes mellitus, Alzheimer y varios tipos de cáncer (4).

La ruta metabólica del ácido araquidónico implica una serie de reacciones químicas cuyos productos están estrechamente relacionados con la inflamación. Las enzimas lipooxigenasas (LOXs) y ciclooxigenasas (COXs) catalizan los primeros pasos de esta ruta, razón por la cual son blancos importantes para el desarrollo de fármacos anti-inflamatorios (5). LOXs catalizan la oxigenación del ácido araquidónico y dan origen a los leucotrienos (LT) y a los hidroxi-eicosatetranoatos (HETE) (6); 
algunos leucotrienos (LTC4, LTD4 y LTE4) son mediadores lipídicos pro-inflamatorios potentes, responsables de la constricción del músculo liso alveolar, hipersecreción de moco y aumento de la permeabilidad vascular en la hiperreactividad alérgica (7). Por su parte, las COXs poseen actividad ciclooxigenasa y peroxidasa; COX-1 se expresa constitutivamente en una amplia variedad de células y está involucrada en la homeostasis celular, mientras que COX-2 es una forma inducible de las COXs y está involucrada en la biosíntesis de prostaglandinas durante la inflamación aguda (8).

Ulomoides dermestoides (Chevrolat, 1878) (= Palembus (Ulomoides) dermestoides $=$ Martianus dermestoides) es un artrópodo del orden coleóptera, familia Tenebrionidae, tribu Diaperinae, género Ulomoides, especie dermestoides. Es originario del sudeste asiático, donde se consume como recurso nutracéutico $(9,10,11)$. En América Latina es usado para tratamiento de la impotencia sexual, asma, artritis, cáncer, tuberculosis y como fortificante $(12,13,14)$. En Colombia su uso se limita a la región Andina, departamentos de Cundinamarca, Huila y Tolima, donde se consumen vivos para el tratamiento del asma (15). En el campo científico, existen algunas publicaciones que reportan actividad farmacológica del U. dermestoides. En 2010, Santos et al. publicaron un estudio que describe las propiedades anti-inflamatorias e inmunomoduladoras de extractos del escarabajo, obtenidos con tampón salino fosfato (16); en 2011, Tobón y colaboradores reportaron que el aceite extraído del $U$. dermestoides tiene efecto depresor del sistema nervioso central de ratones albinos (Mus musculus) en dosis de $3 \mathrm{mg} / \mathrm{Kg}$, administrada por vía oral (17); mientras que dos estudios independientes describieron las propiedades antioxidantes de hidrolizados de proteínas (18), extractos acuosos (19) y metanólicos del $U$. dermestoides (20).

El propósito del presente estudio fue obtener extractos acuosos de $U$. dermestoides adultos y explorar, mediante ensayo in vitro, su potencial para inhibir tres enzimas involucradas en la biosíntesis de reguladores de la inflamación, 15-LOX, COX-1 y COX-2.

\section{MATERIALES Y MÉTODOS}

\section{Muestra}

La identidad taxonómica de la especie Ulomoides dermestoides fue realizada siguiendo las claves publicadas por Kim \& Jung, 2005 (21) y posteriormente validada en el Departamento de Entomología del Instituto de Ciencias Naturales de la Universidad Nacional, Bogotá, Colombia (código de colección ICN-45905).

Se realizó un cultivo a partir de un pie de cría establecido en el Laboratorio de Productos Naturales de la Universidad del Atlántico. Los escarabajos se mantuvieron bajo condiciones controladas detemperatura $\left(27 \pm 2^{\circ} \mathrm{C}\right)$ yhumedad relativa $(70-75 \%)$ y se alimentaron únicamente con pan integral y salvado de trigo. Después de 90 días de cultivo, los individuos adultos se separaron del sustrato y se almacenaron en tubos de polipropileno de $50 \mathrm{~mL}$ a temperatura de $-70^{\circ} \mathrm{C}$ en un congelador Panasonic VIP Eco Freezers Serie MDF-DU700VH-PE.

\section{Extractos}

La escarabajos congelados se trituraron en mortero bajo una corriente de nitrógeno líquido hasta obtener un material pulverizado, el cual fue posteriormente deslipidado con éter dietílico (Merck®), en un extractor Soxleth de $250 \mathrm{~mL}$. Luego, el exceso de éter se evaporó en una cabina de extracción de gases y humos Air flux modelo c100X.

El sólido obtenido se sometió a extracción con las soluciones descritas en la tabla 1. Todos los reactivos usados para la preparación de las soluciones fueron marca Merck. 
Dary Luz Mendoza Meza, Karen Sánchez Catalán y Stephanie Saavedra Ahumada

Tabla 1. Composición de las soluciones de extracción (tampón de lisis) de proteínas del escarabajo Ulomoides dermestoides. PBS: siglas en inglés para tampón salino fosfato; SDS: siglas en inglés para dodecilsulfato sódico.

\begin{tabular}{clc}
\hline Tratamiento & \multicolumn{1}{c}{ Tampón de lisis } & $\mathrm{pH}$ \\
\hline A1 & $\mathrm{NH}_{4} \mathrm{HCO}_{3}$ 0,1M / Tween-20 0,1\% v/v & 7,5 \\
A2 & $\mathrm{NH}_{4} \mathrm{HCO}_{3}$ 0,1M / SDS 0,1\% p/v & 7,5 \\
B1 & $\mathrm{PBS} \mathrm{0,01M} \mathrm{/} \mathrm{Tween-20} \mathrm{0,1 \%} \mathrm{v/v}$ & 7,2 \\
B2 & PBS 0,01M / SDS 0,1\% p/v & 7,2 \\
\hline
\end{tabular}

Las condiciones de extracción fueron: relación peso de material pulverizado/ volumen de tampón de lisis $=1: 10 \mathrm{p} / \mathrm{v}$; temperatura de extracción $=4^{\circ} \mathrm{C}$; velocidad de agitación $=200 \mathrm{rpm}$; tiempo de extracción $=24 \mathrm{~h}$. Los homogenizados obtenidos se centrifugaron a $5.000 \times$ g durante 20 min y temperatura de $4^{\circ} \mathrm{C}$ en un equipo Beckman modelo GPR. El sobrenadante se separó y dializó frente a agua MQ $\left(18,2 \mathrm{M} \Omega \cdot \mathrm{cm}\right.$ a $\left.25^{\circ} \mathrm{C}\right)$ durante $16 \mathrm{~h}$ a $4^{\circ} \mathrm{C}$, en membranas con tamaño de exclusión de 3.500 Dalton (Spectrum Laboratories Inc). El producto de la diálisis se liofilizó por $48 \mathrm{~h}$ a $-46^{\circ} \mathrm{C}$ y 0,098 mbar, en un equipo LABCONCO $®$ FreezeDryer de 2.5 L. Los liofilizados se almacenaron en frascos de vidrio color ámbar a temperatura de $-20^{\circ} \mathrm{C}$ en un congelador Panasonic (Biomedical Freezer Serie MDF-U5412).

Determinación de proteína total. Se realizó mediante micro-ensayo de Bradford (22), usando el estuche comercial QuickStart ${ }^{\mathrm{TM}}$ Bradford Protein Assay de Bio-Rad. Inicialmente se construyó una curva patrón con la proteína BGG (siglas en inglés para Gamma Globulina Bovina), para lo cual se prepararon ocho diluciones, a partir de una concentración inicial de $2 \mathrm{mg} / \mathrm{mL}$ $\left(y=0,0157 x-0,0085 ; R^{2}=0,9973\right)$.

Un volumen de $150 \mu \mathrm{L}$ de cada muestra se mezcló con $150 \mu \mathrm{L}$ del reactivo de Bradford 1X, en placas de titulación de 96 pozos marca NuncImmuno $^{\text {TMM MicroWell }}{ }^{\mathrm{TM}}$ (ThermoScientific ${ }^{\circledR}$ ). Las muestras se incubaron por $10 \mathrm{~min}$, luego se leyó la absorbancia a $595 \mathrm{~nm}$ en un lector de placas multimodal Synergy HTX (BioTek ${ }^{\circledR}$ Instruments, Inc). Las lecturas fueron analizadas con el software Gen5 ${ }^{\mathrm{TM}}$ Data Analysis (BioTek®). La concentración de proteínas se calculó extrapolando la absorbancia de las muestras (extractos) en la curva patrón de BGG.

Perfil electroforético. Todos los reactivos usados en este procedimiento fueron de la marca Bio-Rad. Inicialmente se analizó el perfil de proteínas de cada extracto mediante electroforesis unidimensional en geles de poliacrilamida (SDS-PAGE), usando un equipo Mini-PROTEAN® Tetra Cell (Bio-Rad $\AA)$. El gel de separación se preparó a una concentración de $12 \% \mathrm{~T}$ ( $\mathrm{T}$ = concentración total de monómeros de acrilamida y bisacrilamida) y el gel concentrador se preparó a la concentración de $4 \%$ C (C = concentración del monómero bisacrilamida), según protocolo descrito por Sambrook\& Russell (23). Se sembraron $10 \mu \mathrm{g}$ de extracto por pozo y el corrido electroforético se realizó a $100 \mathrm{~V}$ por $90 \mathrm{~min}$; posteriormente, los geles fueron teñidos con azul de Coomassie R-250 durante 12 horas, luego se decoloraron en una solución de ácido acético al 10\% v/v y se visualizaron en un fotodocumentador UVP ImagingSys EC3 410 LMS-26 97-0279-01 (Bio-Rad®).

Los extractos también se analizaron mediante electroforesis bidimensional, este procedimiento se realizó en el Laboratorio de Genómica y Proteómica de la Universidad Metropolitana de Barranquilla. La muestra (50 $\mu$ g por ensayo) se corrió en una primera dimensión para la separación de proteínas por su punto isoeléctrico (isoelectroenfoque o IEF) en un equipo PROTEAN® ${ }^{\circledR} 12^{\mathrm{TM}} \mathrm{IEF}$ Systemde BioRad, usando tiras de $7 \mathrm{~cm}$ de longitud con un 
gradiente de $\mathrm{pH}$ inmovilizado entre 3 y 10. La segunda dimensión fue corrida en el equipo Mini-PROTEAN® (Bio-Rad $\left.{ }^{\circledR}\right)$, usando el marcador de peso molecular PrestainedSDSPAGE Standards Broad Range de Bio-Rad. Finalizado el corrido electroforético, los geles se tiñeron con el colorante fluorescente Oriole (Bio-Rad $\AA$ ), posteriormente las imágenes fueron adquiridas con el equipo ChemiDoc ${ }^{\mathrm{TM}} \mathrm{MP}$ System y analizadas con el Software ImageLab ${ }^{\mathrm{TM}}$ (Bio-Rad®).

Perfil enzimático hidrolasa de los extractos. Se determinó mediante la prueba semicuantitativa comercial api ${ }^{\circledR}$ Zym de BioMèriux ${ }^{\circledR}$ S.A France, Lyon (Referencia \#25 200). El extracto acuoso se diluyó con tampónTris- $\mathrm{NaCl1X}(\mathrm{pH} 7,5)$ hasta una concentración final de $1 \mathrm{mg} / \mathrm{mL}$. Un volumen de $65 \mu \mathrm{L}$ del extracto diluido se agregó a cada cúpula de reacción del api® Zym, las cuales contenían los sustratos para 19 hidrolasas y un control negativo de la prueba. La reacción se incubó por 5 horas a $37^{\circ} \mathrm{C}$, posteriormente se agregó a cada cúpula una gota de reactivo Zym A (composición por $100 \mathrm{~mL}$ : 25g de Tris; $11 \mathrm{~mL}$ de $\mathrm{HCl} 37 \%$; $10 \mathrm{~g}$ de SDS) y otra de Zym B (composición: 0,35\% de Fast Blue BB en 2-metoxietanol). Los resultados se interpretaron siguiendo el instructivo de la casa comercial.

Actividad inhibitoria lipoxigenasa (LOX). La prueba de inhibición lipoxigenasa fue desarrollada mediante un método colorimétrico, usando el estuche comercial "Lipoxygenase Inhibitor Screening Assay Kit" de Cayman Chemicalco (Referencia \#760700). Las soluciones provistas por el estuche fueron: tampón de reacción Tris- $\mathrm{HCl} 0,1 \mathrm{M}(\mathrm{pH} 7,4)$, agentes desarrolladores de color 1 y 2 (cromógeno), estándar de la enzima 15-lipoxigenasa (15LOX) de soja, sustrato (ácido araquidónico), inhibidor inespecífico de 15-LOX (Acido Nordihidroguayarético, NDGA) y $\mathrm{KOH} 0,1 \mathrm{M}$. El tampón de reacción, el cromógeno, la enzima 15-LOX y el sustrato se prepararon como indica el fabricante.
Las reacciones se desarrollaron en una placa de titulación de 96 pozos provista por el kit. El protocolo incluyó la realización de un blanco (100 $\mu \mathrm{L}$ tampón de reacción), un control positivo de la enzima $(10 \mu \mathrm{L}$ de la enzima $15-$ LOX y $990 \mu \mathrm{L}$ del tampón de reacción), un control positivo de la inhibición $(100 \mu \mathrm{L}$ de NDGA, a la concentración de $100 \mu \mathrm{M} /$ pozo) y las muestras $(10 \mu \mathrm{L}$ de la solución de la enzima 15-LOX, $980 \mu \mathrm{L}$ del tampón de reacción y $10 \mu \mathrm{L}$ de los extractos de $U$. dermestoides). Para esta prueba, la concentración de proteína total en las muestras se ajustó a $1 \mathrm{mg} / \mathrm{mL}$; adicionalmente, para establecer el efecto de la concentración de proteína en la actividad inhibitoria 15-LOX, se realizó un ensayo variando la concentración de proteína total desde 0,4 a 1,4 mg/mL.

Las reacciones se iniciaron con la adición de $10 \mu \mathrm{L}$ del ácido araquidónico $(91 \mu \mathrm{M} /$ pozo $)$ al control positivo y a los pozos de las muestras. El plato fue cubierto y ubicado en un agitador GEMINI Twin Shaking Water Bath (RobbinsScientific $\left.{ }^{\circledR}\right)$ a velocidad de $30 \mathrm{rpm}$ y temperatura de $37^{\circ} \mathrm{C}$ por 5 min. Posteriormente, la catálisis enzimática se detuvo con $100 \mu \mathrm{L} /$ pozo del cromógeno. La cantidad de hidroperóxidos (HP) producidos en la reacción se midió en un lector de placas multimodal Synergy HTX, a longitud de onda de $420 \mathrm{~nm}\left(\mathrm{Ab}_{420 \mathrm{~nm}}\right)$. El efecto inhibitorio se calculó usando la ecuación 1. Donde: \% I corresponde al porcentaje de inhibición de la enzima 15-LOX, $H P_{\text {blanco }}$ es la absorbancia del blanco y $H P_{\text {muestra }}$ es la absorbancia de la muestra.

$$
\% I=\frac{H P_{\text {biante }}-H P_{\text {miestra }}}{H P_{\text {bierco }}} \times 100
$$

Adicionalmente, para establecer posible interferencia de la muestra con el ensayo, la reacciones se repitieron reemplazando la enzima 15-LOX con peróxido de hidrógeno $420 \mu \mathrm{M}$ (Merck®). La interpretación se hizo de acuerdo con las recomendaciones de la casa comercial, donde la absorbancia del blanco más la muestra (inhibidor) debía ser $<0.2$. Adicionalmente, 
los valores de absorbancias del peróxido de hidrógeno con o sin las muestras (inhibidor) debían ser similares.

Actividad inhibitoria ciclooxigenasa (COX). Fue evaluada mediante inmunoensayo enzimático usando el estuche comercial "COX (ovine/human) Inhibitor Screening Assay Kit" de Cayman Chemicalco (Referencia \# 560131).

El método se desarrolló en los siguientes pasos: a) síntesis del endoperóxido PGF2 $\alpha$, a partir del ácido araquidónico (sustrato) y la enzima COX suministrada en el kit; b) detección del PGF2 $\alpha$ mediante un inmunoensayo enzimático competitivo (nombre abreviado: EIA). En este último paso, el producto PGF2 $\alpha$ se une a un anticuerpo específico desarrollado en conejo (anti-PG), el cual se encuentra unido a los pozos de una placa de titulación suministrada por el kit. Las moléculas del anticuerpo anti-PG que no se unen a la PGF2 $\alpha$ (anti-PG libres), son detectadas por un trazador PG-AChE (protaglandina, conjugado con la enzima acetilcolinesterasa). La actividad de AChE se detecta con el reactivo de Ellman, generándose un compuesto coloreado que presenta fuerte absorción a longitud de onda de $412 \mathrm{~nm}$. La intensidad del color generado en el inmunoensayo enzimático $\left(A b_{412 \mathrm{~mm}}\right)$, es proporcional a la cantidad del PG-AChE unido al pozo de reacción, el cual es inversamente proporcional a la cantidad de PG libre presente en el pozo durante la incubación.

La síntesis de PGF2 $\alpha$ se realizó en tubos de reacción de $0,5 \mathrm{~mL}$, en los cuales se mezcló $160 \mu \mathrm{L}$ del tampón de reacción (Tris-HCl 0,1M pH 8,0/ EDTA 5mM/fenol $2 \mathrm{mM}$ ), $10 \mu \mathrm{L}$ del reactivo Heme y $10 \mu \mathrm{L}$ de la enzima (COX-1 o COX-2) previamente disuelta en tampón de reacción. El tubo se agitó por vórtex y se le adicionó la muestra problema (extractos acuosos de $U$. dermestoides disueltos en PBS 0,01 mM, $10 \mu \mathrm{g} /$ reacción), seguido de incubación por 5 $\min$ a $37^{\circ} \mathrm{C}$. Luego se adicionó a los tubos 10 $\mu \mathrm{L}$ del sustrato (ácido araquidónico, $100 \mu \mathrm{M}$ / reacción) y se incubó por 5 min. La catálisis se detuvo por adición de $\mathrm{HCl}(1 \mathrm{M})$, seguido por reducción química del producto (PGH2 $\alpha$ ) con solución saturada de $\mathrm{SnCl}_{2}(30 \mu \mathrm{L} /$ reacción). La actividad COX se midió basados en la cantidad de prostaglandina que se produjo en el tubo de reacción y que fue detectada por el inmunoensayo EIA.

Adicionalmente, se construyó una curva de referencia con un estándar de la prostaglandina $\mathrm{H} 2$ (PGH2), suministrado en el estuche comercial (concentraciones desde 2000 a $15,6 \mathrm{pg} / \mathrm{mL}$ ), partir de la cual se calcularon las concentraciones de PGF2 $\alpha$ que se produjeron en presencia del inhibidor (PGF2 $\alpha_{\text {muestra }}$ ) y ausencia del inhibidor $\left(\right.$ PGF $\left.2 \alpha_{100 \%}\right)$. También se incluyó un control del solvente, cuya absorbancia fue restada a las lecturas de las muestras. El porcentaje de inhibición de la enzima COX $(\% I)$ se calculó usando la ecuación 2.

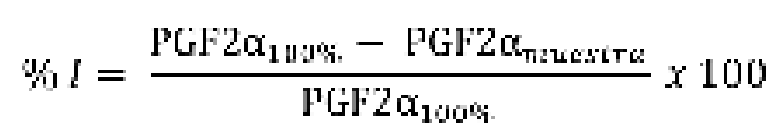

\section{Análisis estadístico}

Los análisis de contenido de proteína total y actividad inhibitoria LOX y COXs se realizaron por triplicado, con cada uno de los extractos. Los resultados se expresaron como valor de la media \pm desviación estándar (DE). Para establecer posible asociación entre los resultados de la inhibición COX-1 y COX-2, se realizó un análisis de varianza (ANAVA) con un nivel de confianza del 99\%, previa comprobación de los supuestos de independencia, normalidad y homocedasticidad de los datos. Adicionalmente, para establecer asociación entre el contenido de proteína en los extractos y la actividad inhibitoria 15-LOX, se realizó un análisis de regresión lineal simple. Todas las pruebas estadísticas se realizaron con el software libre $\mathrm{R}$ (www.r-project.org). 


\section{RESULTADOS}

Muestra. Los individuos de la especie Ulomoides dermestoides usados en esta investigación presentaron una coloración entre marrón rojizo y marón oscuro. Los principales caracteres morfológicos usados para la confirmación de la identidad del escarabajo se presentan en la figura 1.
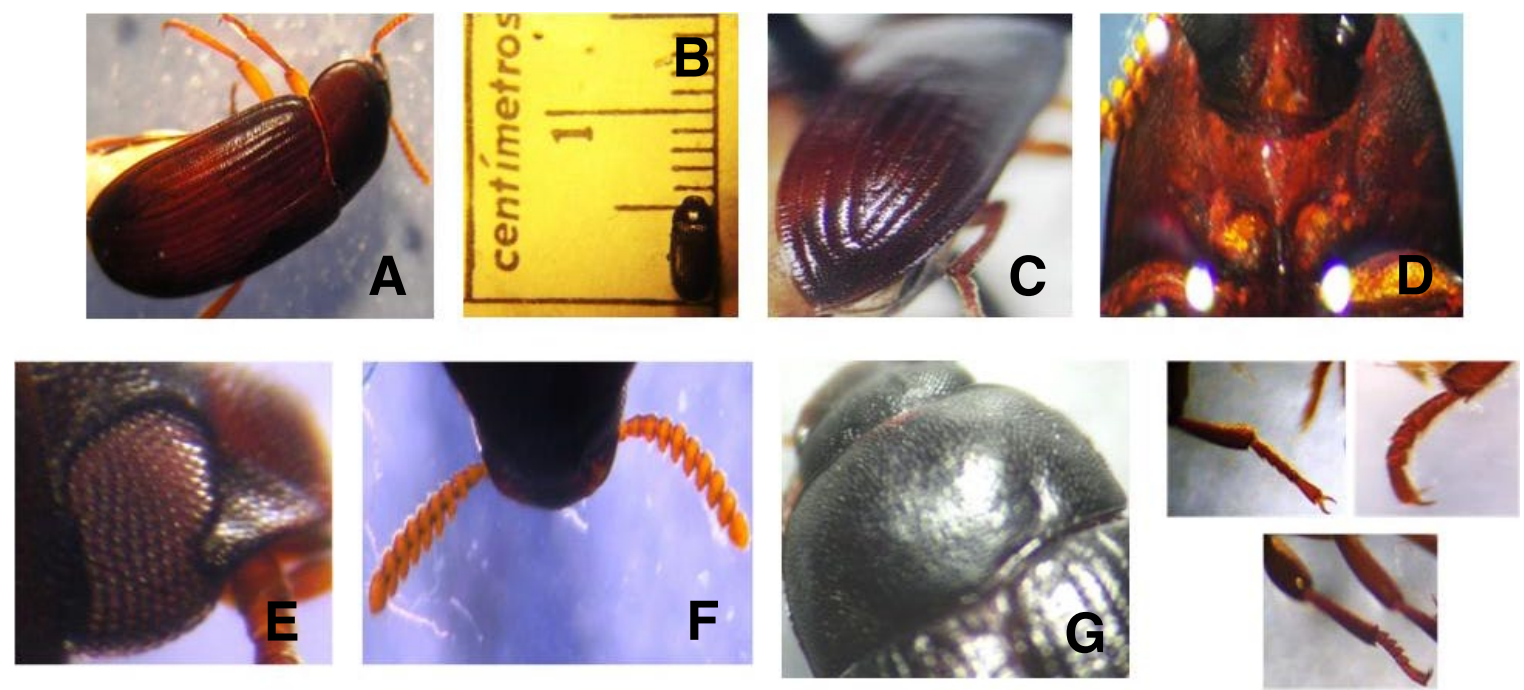

Figura 1. Carácteres morfológicos de $U$. dermestoides. A. Cuerpo en forma oblonga y color sombrio; $\mathrm{B}$. Longitud de 5-6 mm; C. Inter-estrías dos y siete unidas al final; D. Frente de cavidad coxal cerrada atrás. E. Ojos prominentes divididos por una cresta dorsal. F. Antenas largas moniliformes. G. Puntuaciones en el pronoto más separadas que en la cabeza. H. Fórmula tarsal 5-5-4.

Extractos. El volumen de los extractos obtenidos estuvo entre 18 y $22 \mathrm{~mL}$, todos presentaron un color ligeramente marrón. Los rendimientos de extracción de proteína soluble total estuvieron entre 1,603 y $0,636 \% p / p$, siendo el método de extracción con la solución B2 (PBS 0,01M /SDS $1 \% \mathrm{v} / \mathrm{v}$ ) el que produjo la mayor concentración de proteína soluble $(32,07 \pm 0,39 \mathrm{mg} / \mathrm{mL}$ de extracto) (tabla 2).

Tabla 2. Concentración y rendimiento de extracción de proteínas solubles totales en extractos acuosos del cuerpo entero de Ulomoides dermestoides adultos, obtenidos con diferentes tampones de extracción.

\begin{tabular}{|c|c|c|c|}
\hline Tratamiento & Solución de extracción & $\begin{array}{c}\text { Proteína } \\
\text { total } \\
{[\mathrm{mg} / \mathrm{mL}]^{*}}\end{array}$ & $\begin{array}{c}\text { Rendimiento } \\
\% \mathrm{p} / \mathrm{p}^{* *}\end{array}$ \\
\hline A1 & $\mathrm{NH}_{4} \mathrm{HCO}_{3} 0,1 \mathrm{M} /$ Tween-20 0,1\% v/v & $12,72 \pm 0,28$ & 0,636 \\
\hline A2 & $\mathrm{NH}_{4} \mathrm{HCO}_{3} 0,1 \mathrm{M} / \mathrm{SDS} 0,1 \% \mathrm{v} / \mathrm{v}$ & $14,43 \pm 0,33$ & 0,721 \\
\hline B1 & PBS 0,01M / Tween-20 0,1\% v/v & $14,76 \pm 0,82$ & 0,738 \\
\hline B2 & PBS 0,01M / SDS 0,1\% p/v & $32,07 \pm 0,39$ & 1,603 \\
\hline
\end{tabular}

* Valor de la media de 3 lecturas \pm DE.

** Expresado como mg de proteína soluble total/100 mg de muestra pulverizada. 
Dary Luz Mendoza Meza, Karen Sánchez Catalán y Stephanie Saavedra Ahumada

Perfil electroforético. En la electroforesis obtenido con la solución de extracción B2 (PBS/ unidimensional se visualizó un perfil de bandas SDS) mostró bandas más intensas y nítidas similar en los cuatro extractos; sin embargo, el (figura 2).

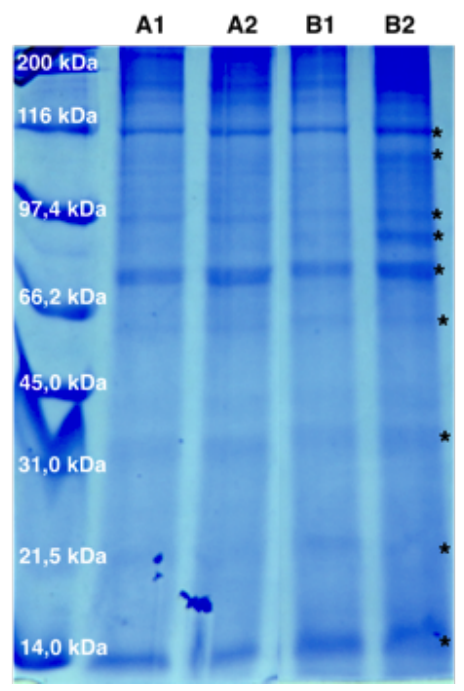

Figura 2. Perfil SDS-PAGE de extractos acuosos de $U$. dermestoides, obtenidos con diferentes tampones de extracción. Carril 1: Marcador de peso molecular (SDS-PAGE Molecular Weight Standards, Broad Range, BIO-RAD); A1: $\mathrm{NH}_{4} \mathrm{HCO}_{3} 0,1 \mathrm{M} /$ Tween-20 0,1\%; A2: $\mathrm{NH}_{4} \mathrm{HCO}_{3}$ 0,1M/SDS 0,1\%; B1: PBS 0,01M/Tween-20 0,1\%; B2: PBS 0,01M/ SDS $0,1 \%$. *Bandas electroforéticas mayoritarias comunes.

La figura 3 muestra los resultados de la de los estándares de peso molecular. El gráfico electroforesis bidimensional del extracto 1 corresponde a la curva de calibración para obtenido con el tampón de extracción B2. el cálculo de los tamaños moleculares que se Se observaron 13 bandas, cuyos tamaños se presentan en la tabla 3.

calcularon con base en la movilidad relativa

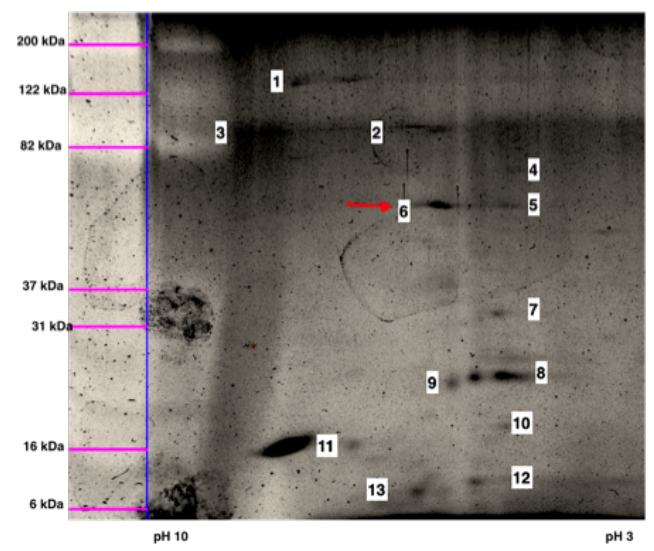

Figura 3.Electroforesis bidimensional de extracto acuoso de Ulomoides dermestoides. El primer carril (izquierda) corresponde al marcador de peso molecular (Prestained SDSPAGE Standards Broad Rangede BIO-RAD). 


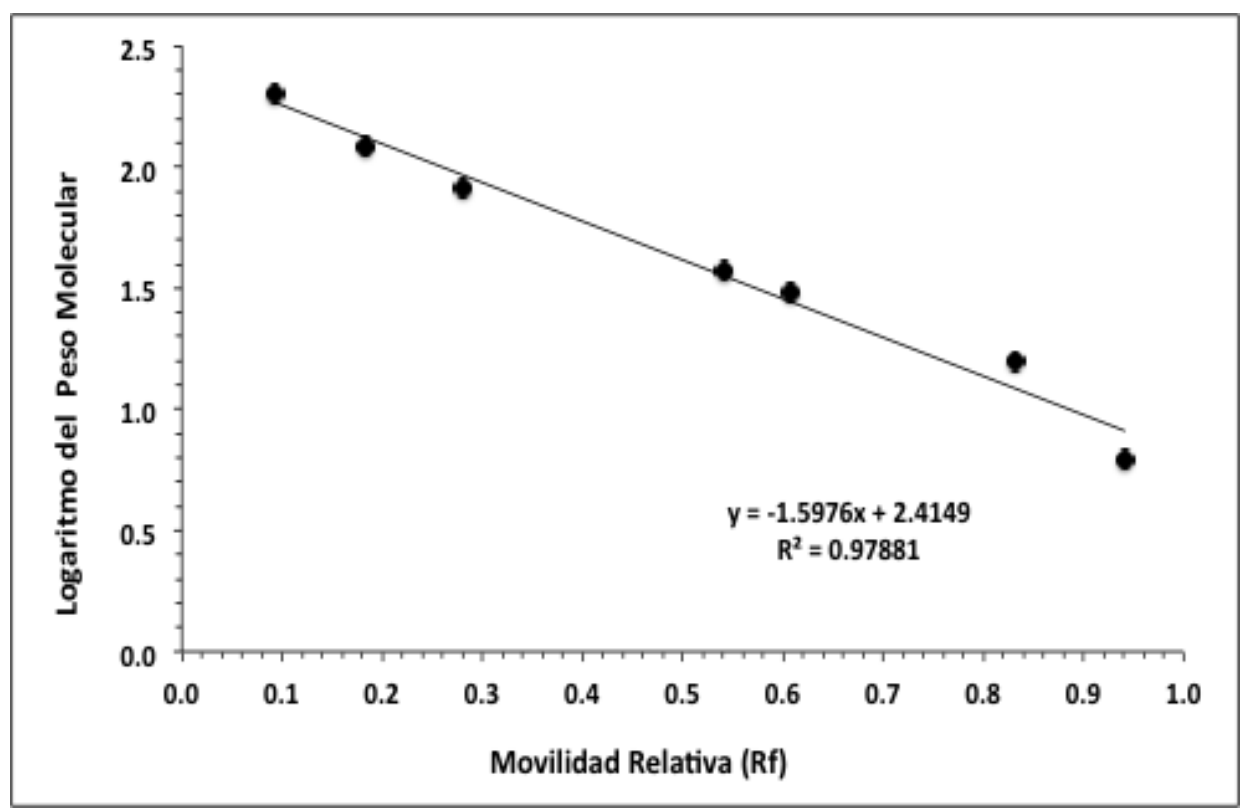

Gráfico1.Curva de calibración para el cálculo de los pesos moleculares relativos, usando el marcador de peso molecular (Prestained SDS-PAGE Standards Broad Rangede BIO-RAD).

Tabla 3. Movilidad relativa y pesos moleculares (P.M.) calculados para las bandas electroforéticas mayoritarias en los extractos acuosos totales de $U$. dermestoides.

Estándar de Peso Molecular

Extracto Ulomoides dermestoides

\begin{tabular}{cccccc}
\hline No. Banda & Movilidad relativa & P.M. (kDa) & No. Banda & Movilidad relativa & P.M. (kDa) \\
\hline 1 & 0,093 & 200,2 & 1 & 0,147 & 151,2 \\
2 & 0,183 & 122,1 & 2 & 0,261 & 99,7 \\
3 & 0,281 & 81,7 & 3 & 0,266 & 97,8 \\
4 & 0,541 & 37,0 & 4 & 0,342 & 74,0 \\
5 & 0,608 & 30,5 & 5 & 0,398 & 60,1 \\
6 & 0,832 & 15,9 & 6 & 0,402 & 59,3 \\
7 & 0,941 & 6,2 & 7 & 0,558 & 33,4 \\
- & - & - & 8 & 0,641 & 24,6 \\
- & - & - & 9 & 0,652 & 23,6 \\
- & - & - & 10 & 0,717 & 18,6 \\
- & - & - & 11 & 0,753 & 16,3 \\
- & - & - & 12 & 0,878 & 10,3 \\
- & - & - & 13 & 0,920 & 8,8 \\
\hline
\end{tabular}


Perfil enzimático hidrolasa de los extractos. El resultado del ensayo api® Zym mostró actividad para 17 sustratos de hidrolasas. La mayor actividad catalítica fue observada para los sustratos de las fosfohidrolasas (fosfatasa alcalina, fosfatasa ácida y naftol-AS$\beta 1$-fosfosfohidrolasa); también para sustratos de la leucina arilamidasa, $\beta$-glucoronidasa, $\alpha$-glucosidasa, $N$-acetil- $\beta$-glucosaminidasa y $\alpha$-manosidasa (figura 4).

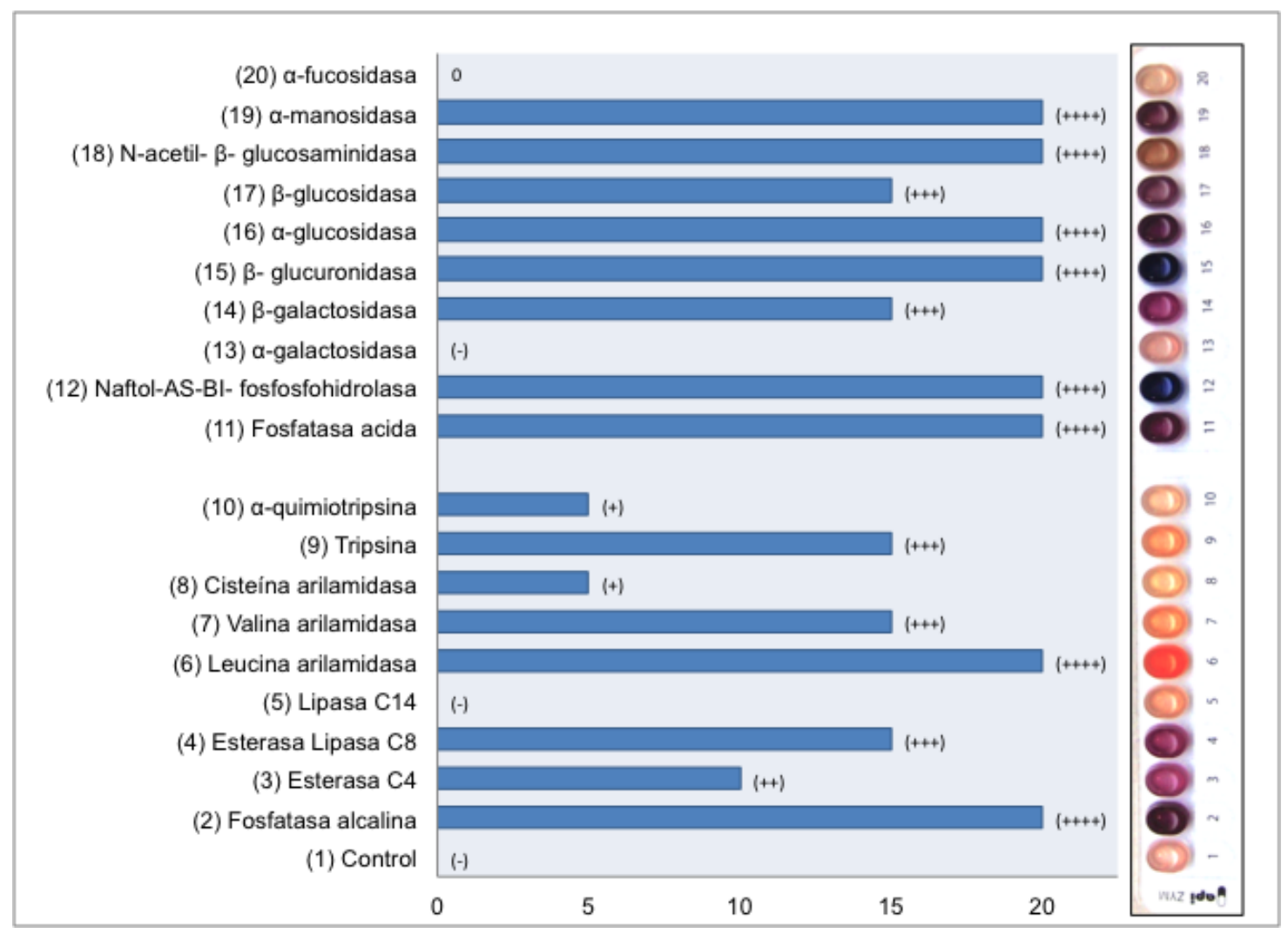

Figura 4. Resultado de actividad enzimática del extracto acuoso $U$. dermestoides, evaluada con el estuche comercial api®-Zym (BioMérieux, France). La cantidad de sustrato hidrolizado fue clasificada y comparada con una carta estándar de lectura semicuantitativa, así: (-) representa 0 nmol, (+): 5 nmol, (++): $10 \mathrm{nmol},(+++): 15$ nmol, (++++): $20 \mathrm{nmol}$.

Actividad inhibitoria 15-LOX. Para conocer si los extractos acuosos de $U$. dermestoides podrían inhibir la actividad de enzimas involucradas en procesos inflamatorios, se desarrolló un ensayo preliminar de inhibición de la enzima 15-LOX de la soja, usando como sustrato ácido araquidónico. Los resultados indican que los extractos obtenidos con PBS presentan un porcentaje de inhibición $>60 \%$, mientras que la actividad de los extractos obtenidos con $\mathrm{NH}_{4} \mathrm{HCO}_{3}$ fue menor del $30 \%$ (figura 5). Adicionalmente, el ensayo con peróxido de hidrógeno, sugiere que la menor actividad de los extractos A1 y A2 estaría relacionada con la presencia de metabolitos que interfieren con el ensayo (figura 6). 


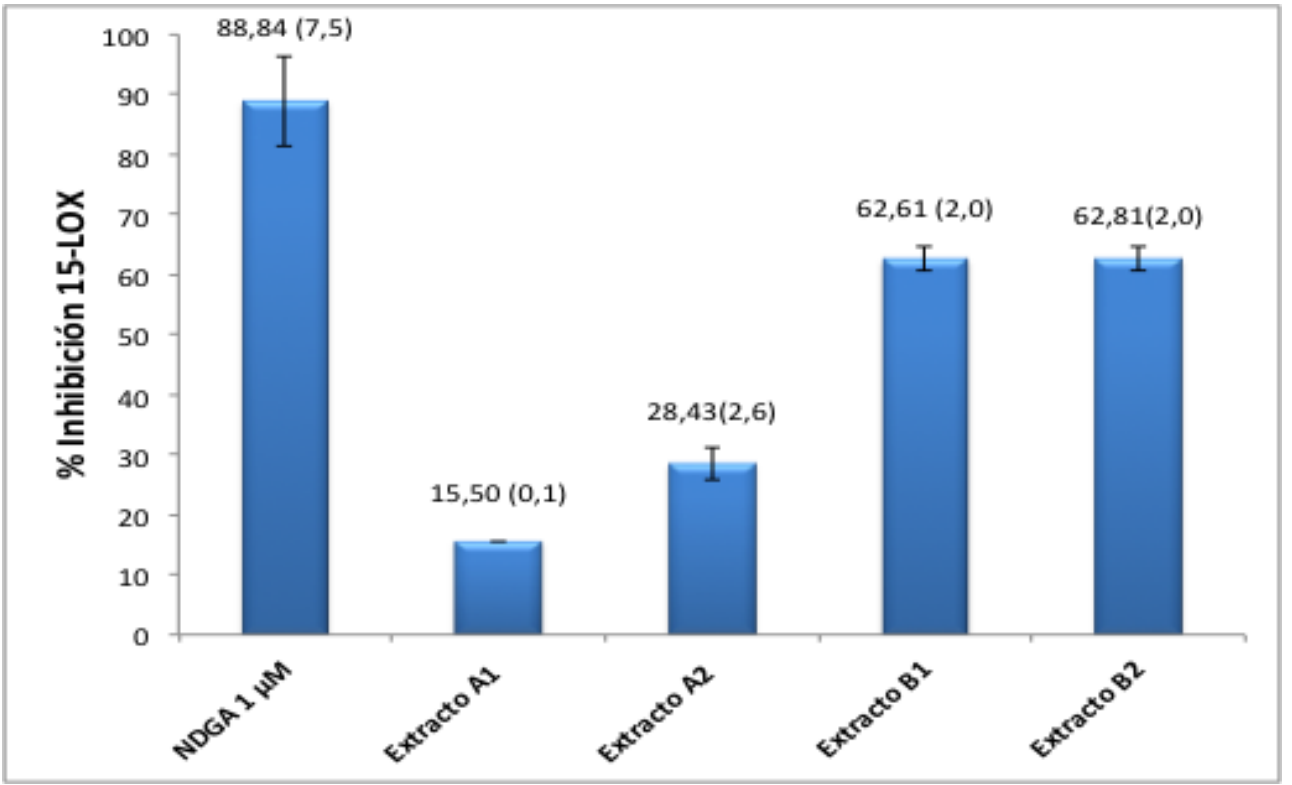

Figura 5. Resultado del ensayo de inhibición in vitro 15-LOXdebido a extractos acuosos totales de $U$. dermestoides (concentración de proteína total $1 \mathrm{mg} / \mathrm{mL}$ ). NDGA = Ácido Nordihidroguayaretico. A1: $\mathrm{NH}_{4} \mathrm{HCO}_{3} 0,1 \mathrm{M}+$ Tween-20 0,1\%v/v; A2: $\mathrm{NH}_{4} \mathrm{HCO}_{3} 0,1 \mathrm{M}+\mathrm{SDS}$ 0,1\%p/v; B1: PBS 0,01M + Tween-20 0,1\%v/v; B2: PBS 0,01M + SDS 0,1\%p/v. Media (DE).

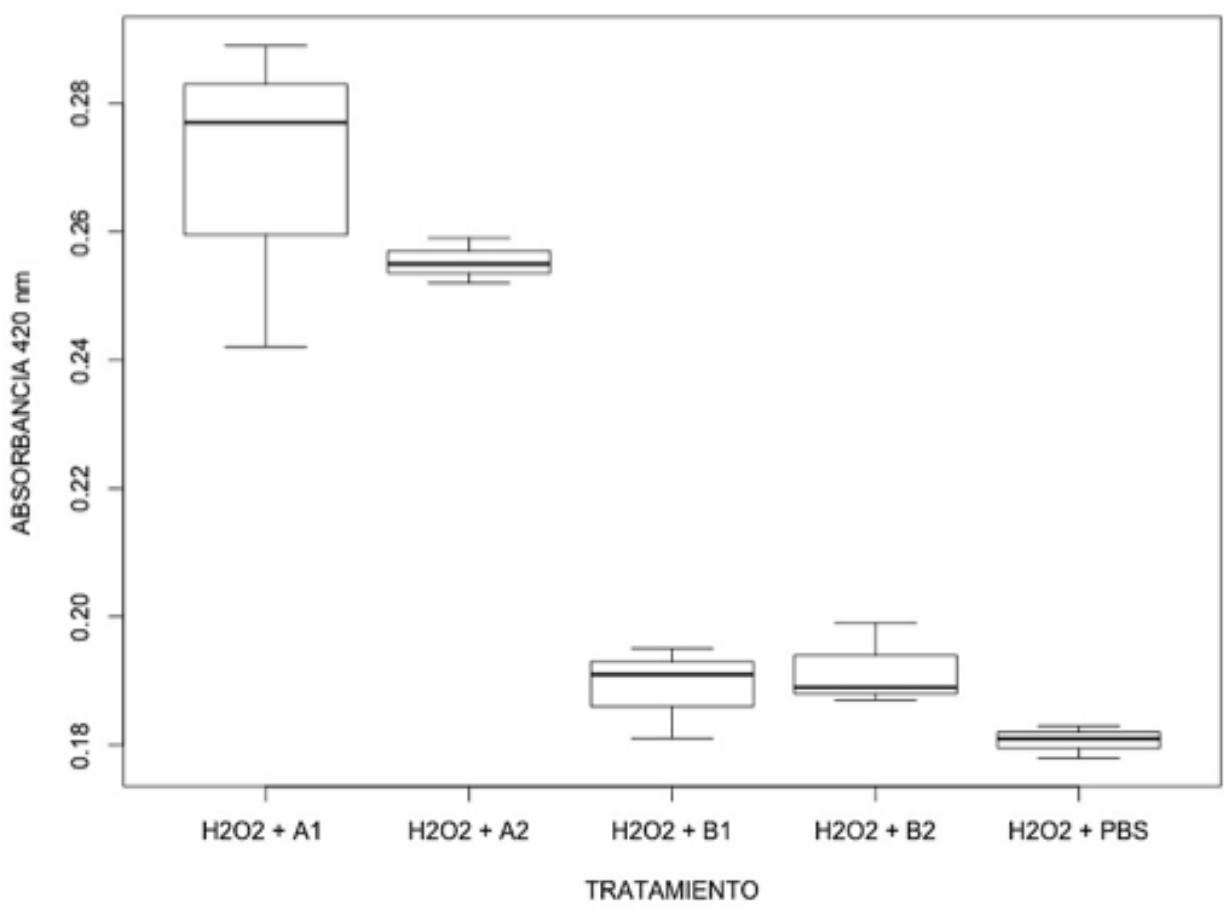

Figura 6. Resultado de la prueba de detección de interferencias en el ensayo de inhibición 15LOX. Note que las absorbancias del peróxido de hidrógeno $\left(\mathrm{H}_{2} \mathrm{O}_{2}\right)$ sin y con los extractos B1 y B2 son similares, pero con los extractos A1 y A2 son significativamente diferentes (valor $p<$ 0,01). PBS = tampón salino fosfato. 
Dary Luz Mendoza Meza, Karen Sánchez Catalán y Stephanie Saavedra Ahumada

Cuando se evaluó la asociación entre la concentración de proteína y la inhibición 15LOX se observó que la actividad inhibitoria disminuía a concentraciones de proteína total mayores a $1 \mathrm{mg} / \mathrm{mL}$ (figura 7 ). Un análisis de regresión simple confirmó que no existe asociación lineal entre la concentración de proteínas y la inhibición 15-LOX (valor $p=0,493$ ). Adicionalmente, se sugiere que concentraciones de proteína $>1 \mathrm{mg} / \mathrm{mL}$ podrían interferir con el ensayo.

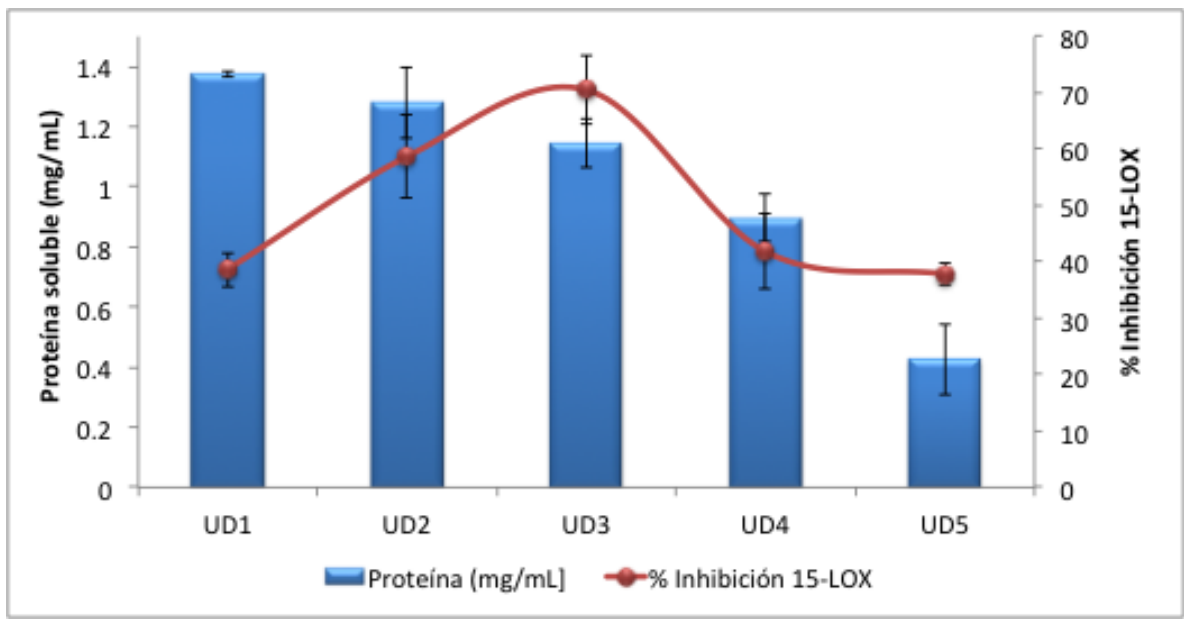

Figura 7. Actividad inhibitoria 15-LOX del extracto acuoso B2 de U. dermestoides, con diferentes concentraciones de proteína total.

Actividad inhibitoria ciclooxigenasa (COX-1 y COX-2). El gráfico 2 presenta la curva estándar con PGH2, utilizada para calcular la cantidad de
PG producida a partir del ácido araquidónico, en presencia del inhibidor (extractos acuosos de U. dermestoides).

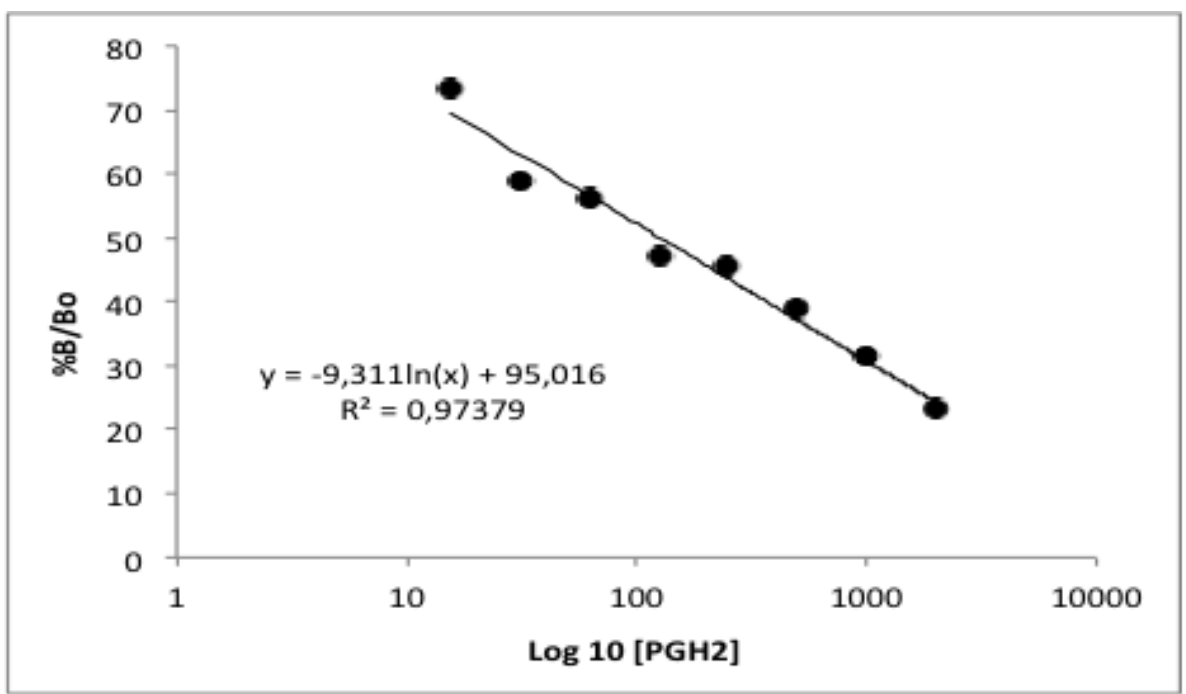

Gráfico 2. Curva estándar PGH2. \%B/B0 = radio de unión del anticuerpo de captura al trazador PG-AChE, en presencia y ausencia de PG libre. 
Todos los extractos acuosos del $U$. dermestoides inhibieron ambas ciclooxigenasas. Cuando se comparó el valor de las medias de los porcentajes de inhibición de COX-1 y COX-2, se observó diferencia estadísticamente significativa con el extracto B2 (valor $p=0,0029$ ), siendo mayor el efecto inhibitorio de la enzima COX-1 $(88,5 \pm 3,9)$. En cuanto a la inhibición de la COX-
2 , ciclooxigenasa involucrada en los procesos de inflamación aguda, el efecto fue mayor con los extractos A2 (91,1 $\pm 1,3 \%)$ y A1 $(62,3 \pm 5,5 \%)$; sin embargo, estos no mostraron diferencia significativa entre la actividad inhibitoria COX-1 y COX-2 ( $p>0,01)$, lo cual sugiere la presencia de inhibidores inespecíficos de las COXs en estos extractos (figura 8).
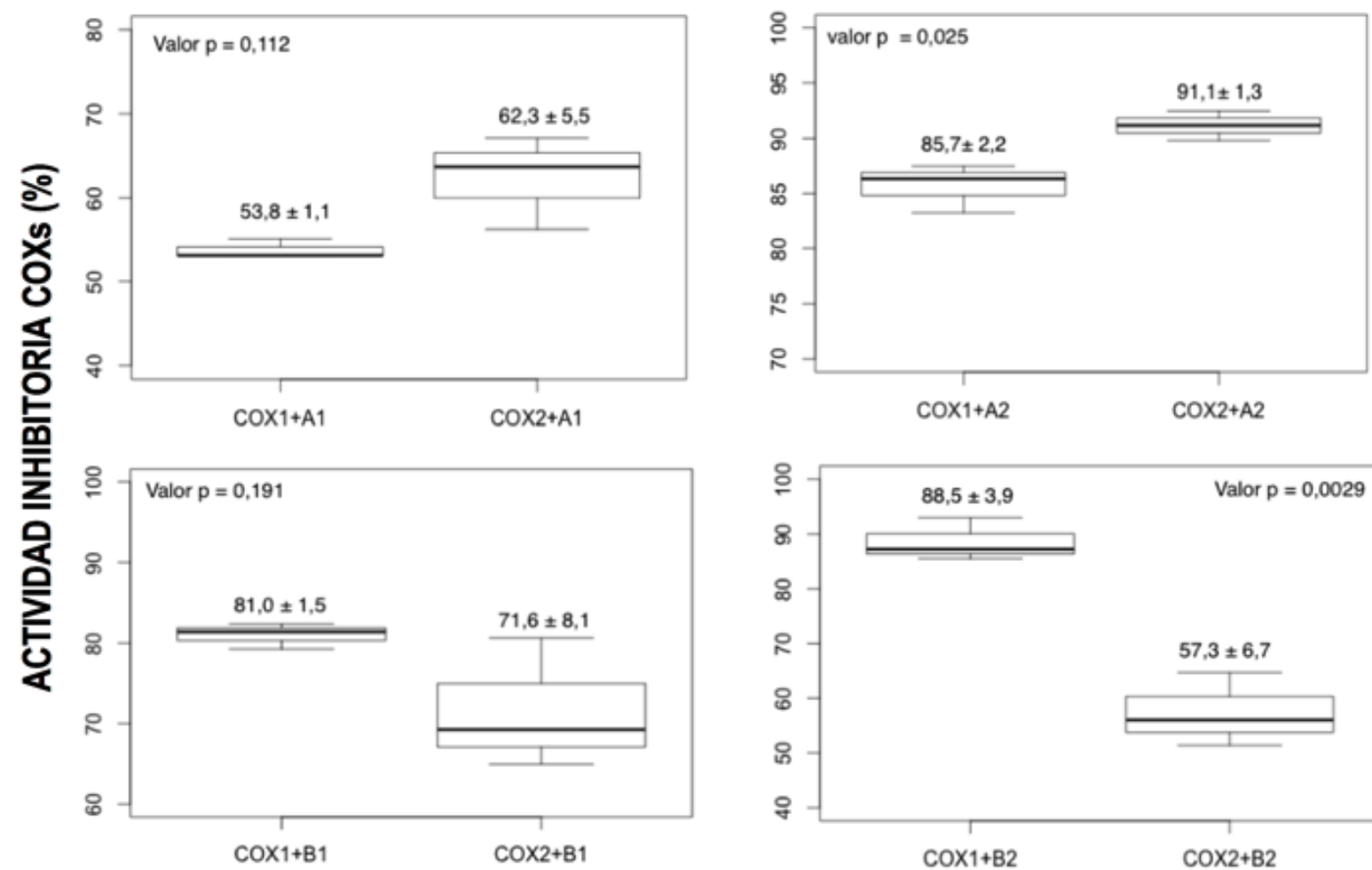

\section{TRATAMIENTOS}

Figura 8. Resultado del ensayo de inhibición In vitrode las enzimas COX-1 y COX-2, debido a los extractos acusos del escarabajo Ulomoides dermestoides. Las letras A1, A2, B1 y B2 representan los extractos del escarabajo obtenidos con los diferentes tampones de extracción. Note que existe diferencia estadisticamente significativa entre las inhibiciones COX-1 y COX-2 con el extracto B2 (valor $p<0,01$ ).

\section{DISCUSIÓN Y CONCLUSIONES}

Algunos estudios realizados con el $U$. dermestoides presentan métodos diferentes para la obtención de sus proteínas y la mayoría de ellos obvian la publicación de los detalles sobre la caracterización bioquímica de los extractos obtenidos. Santos et al. en 2010 (16), utilizaron PBS para obtener extractos acuosos de $U$. dermestoides, usando una relación de $1 \mathrm{~g}$ de escarabajos por $2 \mathrm{~mL}$ de tampón y un tiempo de extracción de 2 min; estos extractos fueron utilizados para evaluar la actividad anti-inflamatoria en ratas $y$ el efecto inmunomodulador en cultivos de 
células polimorfonucleares (PMN). También se describió un método para extraer la enzima superóxidodismutasa (SOD) desde el escarabajo adulto, el cual incluyó la pulverización de los escarabajos en nitrógeno líquido, seguido de extracción con solución de $\mathrm{NaCl} 0,13 \mathrm{M}$, usando una relación de $1 \mathrm{~g}$ de escarabajo por $13 \mathrm{~mL}$ de solución y tiempo de extracción de $14 \mathrm{~h}(24,25)$. A diferencia de estos trabajos, la metodología presentada en nuestro estudio incluye un paso previo de deslipidación de los escarabajos, así como la adición de un detergente a la composición de los tampones de extracción; como resultado, se observó que la adición de SDS 0,1\% al tampón PBS incrementó, en aproximadamente el doble, la cantidad de proteína soluble obtenida, este resultado fue atribuido a la propiedad del SDS para solubilizar proteínas asociadas a membranas o que hacen parte de otras estructuras complejas (26).

Por otra parte, el resultado de la SDS-PAGE permitió verificar la integridad de las proteínas presentes en los extractos. Todos los extractos mostraron un perfil común de bandas nítidas, lo cual sugiere que cambios en la composición de los tampones de extracción evaluados, no causan desnaturalización de las proteínas, pero sí afectan la eficiencia en la solubilización y extracción de las mismas.

El resultado con api® Zym mostró que los extractos presentan actividad catalítica hidrolasa para 17 de los 19 sustratos incluidos en el estuche comercial. El api ${ }^{\circledR}$ Zym se ha utilizado ampliamente en la caracterización de extractos microbianos $(27,28)$ y también extractos alergénicos de artrópodos, por ejemplo, extractos de ácaros de importancia médica $(29,30)$. Las hidrolasas cumplen funciones fisiológicas y metabólicas importantes en los artrópodos, como son la digestión y el desarrollo morfológico. Los resultados con el extracto B2 del $U$. dermestoides mostraron elevada actividad catalítica para tres fosfohidrolasas, lo cual sugiere alta actividad metabólica; adicionalmente, las actividades esterasa ( $\mathrm{C} 4$ y C8), endopeptidasas (tripsina y $\alpha$-quimiotripsina), exopeptidasas (leucina y valinaarilamidasas) y carbohidrasas (galactosidasas, glucosidasas y manosidasas) son necesarias para la digestión de lípidos, proteínas y carbohidratos presentes en la dieta del escarabajo; mientras que, la actividad $\mathrm{N}$-acetilo- $\beta$-glucosaminidasa es necesaria para la remodelación de la quitina en el exoesqueleto $(31,32)$. La actividad quitinasa también tiene importancia biomédica ya que estas proteínas pueden actúan como alérgenos importantes (33), sobre todo en personas sensibilizadas a otros artrópodos (34). Alergia a los coleópteros es poco reportada, sin embargo dos estudios realizados previamente describen alergia ocupacional ocasionada por el escarabajo rojo de la harina, el Tribolium confusum (Herbst, 1797) $(35,36)$.

Encuanto a la actividad inhibitoria lipooxigenasa, ésta no ha sido reportada previamente para extractos acuosos del cuerpo entero de $U$. dermestoides. Sin embargo, un trabajo realizado con extractos acuosos de glándulas pigidiales del escarabajo Palembus ocularis (Casey, 1891), demostró la capacidad de estos extractos para inhibir la síntesis del leucotrieno LTB4 y del hidroperóxido 5-HETE, en un modelo experimental con neutrófilos extraídos de sangre fresca humana (37). Los autores atribuyeron el efecto LOX inhibitorio a las hidroquinonas y benzoquinonas almacenadas en las glándulas pigidiales de este escarabajo (secreción de defensa).

En términos de estructura y función, las LOXs son únicas debido a que su cofactor metálico $\left(\mathrm{Fe}^{3+}\right)$ se encuentra unido a cadenas laterales cercanas al extremo C-terminal de la enzima, lo cual permite a los inhibidores interactuar con el cofactor o unirse directamente a él (38). Debido a que la inhibición de LOXs depende del estado de oxidación del hierro, el primer modo de inhibición planteado fue a través de la reducción directa del hierro a su forma inactiva $\left(\mathrm{Fe}^{2+}\right)$; los modos de inhibición dos y tres implican la formación directa de complejos con el hierro férrico y la reducción efectiva de los 
hidroperóxidos (HETE), respectivamente (39). La literatura científica presenta un amplio número de sustancias químicas que pueden inhibir a las LOXs de la soja, incluidos compuestos fenólicos (40), quinonas (41) y lípidos resorcinólicos (42); este tipo de compuestos podrían estar presentes en los extractos polares del $U$. dermestoides (20).

El efecto inhibitorio de COX-1 y COX-2, observado en este estudio, sugiere una explicación bioquímica para las propiedades anti-inflamatorias atribuidas al $U$. dermestoides. La actividad anti-inflamatoria in vivo de extractos acuosos del escarabajo fue reportada previamente (16), usando un modelo de inflamación aguda por inyección de carragenina en el cavidad pleural de ratas Wistar, encontrando que el grupo de animales tratados con $8 \mathrm{y}$ $16 \mathrm{mg}$ del extracto/Kg de peso, presentaron disminución de los parámetros de inflamación, a saber: número de leucocitos totales, células polimorfonucleares (PMN), concentración de proteínas plasmáticas y volumen de exudado pleural. Los autores atribuyen esta respuesta a una probable disminución de la liberación de factores quimiotácticos, responsables de reclutar las células en el sitio de la lesión; también relacionan el efecto antiinflamatorio con la posible presencia de proteínas, como las cistatinas, las cuales interfieren con el proceso inflamatorio a través de mecanismos celulares (43).

Por otra parte, compuestos presentes en la secreción de defensa de los coleópteros, como Tribolium castaneum (Herbst, 1797), han sido reportados como inhibidores de otra enzima de la ruta del ácido araquidónico, la PGE2; experimentos publicados por Jurenka (1986) y Howard et al., (1986), muestran que derivados hidróxilados del ácido benzoico, presentes en insectos, son inhibidores de PGE2, tan eficientes como el ácido salicílico $(44,45)$. Adicionalmente, se ha encontrado que el ácido protocatecuico, un compuesto fenólico identificado en la cutícula de coleópteros como Tenebrio molitor (Linnaeus, 1758) (46), puede reducir la síntesis de PGE2 y la expresión de COX-2 en ratas (47). Este ácido fenólico también puede formar un complejo con las LOXs (48), lo cual podría explicar el carácter dual de inhibición LOX y COXs observado en el presente estudio, con los extractos acuosos del U. dermestoides.

En conclusión, nuestros resultados demuestran que extractos acuosos de cuerpo entero de $U$. dermestoides adultos presentan un perfil complejo de proteínas solubles involucrados en procesos fisiológicos vitales para el ciclo de vida del escarabajo; estas proteínas también podría contribuir a las propiedades etno-farmacológicas atribuidas al consumo del $U$. dermestoides. Adicionalmente, se sugiere que compuestos no proteicos, como fenoles y derivados de quinonas, presenten en los extractos acuosos del coleóptero, podrían inhibir enzimas de la ruta del ácido araquidónico, específicamente a las lipooxigenasas. Para confirmar está hipótesis es necesario realizar experimentos de inhibición con los compuestos purificados o con fracciones que los contengan. 


\section{REFERENCIAS BIBLIOGRÁFICAS}

1. Scrivo R, Vasile M, Bartosiewicz I, Valesini G. Inflammation as "common soil" of the multifactorial diseases. Autoimmun Rev. 2011; 10 (7):369-74. doi:10.1016/j.autrev.2010.12.006.

2. Crusz SM, Balkwill FR. Inflammation and cancer: advances and new agents. Nat Rev ClinOncol. 2015; 12(10):584-96. doi:10.1038/nrclinonc.2015.105.

3. Medzhitov R1. Origin and physiological roles of inflammation. Nature. $2008 ; 454(7203): 428-35$. doi: $10.1038 /$ nature07201.

4. Kotas ME, Medzhitov R. Homeostasis, inflammation, and disease susceptibility. Cell. 2015; 160(5):81627. doi: $10.1016 /$ j.cell.2015.02.010.

5. Murakami M, Kudo I. Prostaglandin E synthase: a novel drug target for inflammation and cancer. Curr Pharm Des. 2006; 12(8):943-54.doi: 10.2174/138161206776055912.

6. Wisastra R, Dekker FJ. Inflammation, cancer and oxidative lipoxygenase activity are intimately linked. Cancers. 2014; 6:1500-21. doi: 10.3390/cancers6031500.

7. Shin K, Hwang JJ, Kwon BI, Kheradmand F, Corry DB, Lee SH. Leukotriene enhanced allergic lung inflammation through induction of chemokine production. ClinExp Med. 2015; 15(3):233-44. doi: 10.1007/s10238-014-0292-7.

8. Marnett LJ, Rowlinson SW, Goodwin DC, Kalgutkar AS, Lanzo CA. Arachidonic acid oxygenation by COX-1 and COX-2. Mechanisms of catalysis and inhibition. J Biol Chem. 1999; 274(33): 22903-6. doi: $10.1074 / j b c .274 .33 .22903$.

9. FAO Regional Office for Asia and the Pacific. Forest insects as food: humans bite back. Proceedings of a workshop on Asia-Pacific resources and their potential for development. Bangkok, Thailand. 2010; 151-60 pp. Disponible en: www.fao.org/docrep/012/i1380e/i1380e00.pdf.

10. Chu GS, Palmieri JR, Sullivan JT. Beetle-eating: a Malaysian folk medical practice and its public health implications. Trop Geogr Med. 1977; 29(4):422-427. PMID: 610028.

11. Sandroni P. Aphrodisiacs past and present: a historical review. ClinAuton Res. 2001; 11(5):303-7. doi: 10.1007/BF02332975.

12. Costa Neto E, Ramos-Elorduy J. Los insectos comestibles de Brasil: etnicidad, diversidad e importancia en la alimentación. Boletín Sociedad Entomológica Aragonesa. 2006; 38:423-42.

13. Crespo R, Villaverde ML, Girotti JR, Güerci A, Juárez MP, de Bravo MG. Cytotoxic and genotoxic effects of defence secretion of Ulomoides dermestoides on A549 cells. J Ethnopharmacol. 2011; 136(1):2049. doi: 10.1016/j.jep.2011.04.056.

14. Deloya-Brito G, Deloya C. Sustancias producidas por el coleóptero Ulomoides dermestoides (Chevrolat, 1878) (Insecta: Coleoptera: Tenebrionidae): efecto anti-inflamatorio y citotóxico. Acta ZoolMex. 2014; 30(3): 665-61. Disponible en: http://www.scielo.org.mx/pdf/azm/v30n3/v30n3a14.pdf.

15. Amat G, Devia N. Estos escarabajos curan el asma. Publicación de la Unidad de Medios de Comunicación de la Universidad Nacional de Colombia (UNIMEDIOS). Bogotá, Colombia. Disponible en: http:// historico.unperiodico.unal.edu.co/ediciones/103/17.html. Consultado Junio 2015.

16. Santos RC, Lunardelli A, Caberlon E, Bastos CM, Nunes FB, Pires MG, Biolchi V, Paul EL, Vieira FB, Resende do Carmo Aquino A, Corseuil E, de Oliveira JR. Anti-inflammatory and immunomodulatory effects of Ulomoides dermestoides on induced pleurisy in rats and lymphoproliferation in vitro. Inflammation. 2010; 33(3):173-9. doi: 10.1007/s10753-009-9171-x.

17. Tobón FA, Gutiérrez GP, Mejía ML. Evaluación del perfil neurofarmacológico del aceite de Ulomoides dermestoides (Coleoptera: Tenebrionidae). Revista Colombiana de Entomología. 2011; 37(2):251-5. Disponible en: http://www.scielo.org.co/pdf/rcen/v37n2/v37n2a16.pdf. 
18. Yan S, Chu Z. Antioxidant effects of delipidized protein hydrolysate from Martianus dermestoides Chevrolat (Coleoptera, Tenebrionidae) beetles. Acta Entomológica Sinica. 2008; 51(8): 804-9. Disponible en: http://www.insect.org.cn/EN/abstract/abstract9541.shtml\#.

19. ShanChun Y, Lei W, Qing L, Yong F. Anti-senile effects of water extraction of Martianus dermestoides (Coleoptera: Tenebrionidae) feeding different foods on aging mice. Acta Entomol Sin. 2009; 52(7): 820-4. Disponible en: http://www.insect.org.cn/EN/abstract/abstract9369.shtml\#.

20. Mendoza DL, Maury C. Evaluación del contenido de fenoles totales y actividad captadora de radicales libres de extractos hidrometanólicos del escarabajo Ulomoides dermestoides (coleoptera: tenebrionidae). Rev. Asoc. Col. Cienc.(Col.). 2013; 25:135-41. Disponible en: http://www. asociacioncolombianadecienciasbiologicas.org/download/revistas/2013/art\%2013.pdf.

21. Kim J, Jung BH. Contribution to the Tribes Diaperini Doyen in Korea (Coleoptera: Tenebrionidae: Diaperinae). Entomological Research. 2005; 35(2):95-100. doi: 10.1111/j.1748-5967.2005. tb00142.x.

22. Bradford M. A Rapid and Sensitive Method for the Quantitation of Microgram Quantities of Protein Utilizing the Principle of Protein Dye Binding. Analytical Biochemistry 1972; 72:248-54. doi: 10.1016/0003-2697(76)90527-3.

23. Sambrook J, Russell D.W. SDS-Polyacrylamide Gel Electrophoresis of Proteins. CSH Protocols. 2006. doi: $10.1101 /$ pdb. prot4540.

24. Yu WG, Zhang BB, Shen YJ, Li Y, Tian YB, Jiang MH. Purification and Characterization of Superoxide Dismutase from Martianus dermestoides Chevrolat. Adv Mat Res. 2013; 773:336-41. doi: 10.4028/ www.scientific.net/AMR.773.336.

25. Long D, Defu C, Beibei Z, Xiaocan L, Jia Y. Optimization of extraction conditions for superoxide dismutase from Martianus dermestoides. Journal of Northeast Forestry University. 2009; 37(4): 6970.Disponible en: http://en.cnki.com.cn/Article_en/CJFDTOTAL-DBLY200904024.htm

26. Le Maire M, Champeil $P$, Møller JV. Interaction of membrane proteins and lipids with solubilizing detergents. BiochimicaetBiophysicaActa (BBA) - Biomembranes. 2000; 1508(1-2):86-111. doi:10.1016/S0304-4157(00)00010-1.

27. Zhao F1, Bi X, Hao Y, Liao X. Induction of viable but non culturable Escherichia coli O157: H7 by high pressure CO2 and its characteristics. PLoS One. 2013; 8(4):e62388. doi: 10.1371/journal. pone.0062388.

28. Budzyńska A, Sadowska B, Więckowska-Szakiel M, Różalska B. Enzymatic profile, adhesive and invasive properties of Candida albicans under the influence of selected plant essential oils. ActaBiochim Pol. 2014; 61(1):115-21. Disponible en: http://www.actabp.pl/pdf/1_2014/115.pdf.

29. Carnés J, Boquete M, Carballada FJ, Gallego MT, Fernández-Caldas E. Enzymatic activity in body and fecal extracts of the storage mite Chortoglyphus arcuatus. Int Arch Allergy Immunol. 2008; 145(3): 207-212.doi:10.1159/000109289.

30. Morales M, Iraola V, Leonor J, Carnés J. Enzymatic Activity of Allergenic House Dust and Storage Mite Extracts. J Med Entomol. 2013. 50(1): 147-54. doi: http://dx.doi.org/10.1603/ME12154.

31. Kramer Kj, Aoki H. Chitinolytic enzymes from pupae of the red flour beetle, Tribolium castaneum. Comp BiochemPhysiol B Biochem Mol Biol. 1987; 86(3):613-21. http://dx.doi.org/10.1016/03050491(87)90457-3.

32. Merzendorfer $\mathrm{H}$, Zimoch $\mathrm{L}$. Chitin metabolism in insects: structure, function and regulation of chitin synthases and chitinases. J Exp Biol. 2003; 206: 4393-441. doi: 10.1242/jeb.00709.

33. Chun Geun Lee. Chitin, Chitinases and Chitinase-like Proteins in Allergic Inflammation and Tissue Remodeling. Yonsei Med J. 2009; 50(1):22-30. doi: 10.3349/ymj.2009.50.1.22. 
34. O'Neil S, Heinrich T, Hales B, Hazell L, Holt D, Fischer K et al. The chitinase allergens Der p15 and Der p18 from Dermatophagoide spteronyssinus. ClinExp Allergy 2006; 36(6):831-9. doi:10.1111/j.13652222.2006.02497.x.

35. Schultze-Werninghaus G, Zachgo W, Rotermund H, Wiewrodt R, Merget R, Wahl R, Burow G, zurStrassen R. Tribolium confusum (confused flour beetle, rice flour beetle) an occupational allergen in bakers: demonstration of IgE antibodies. Int Arch Allergy ApplImmunol. 1991; 94(1-4):371-2. doi:10.1159/000235407.

36. Alanko K, Tuomi T, Vanhanen M, Pajari-Backas M, Kanerva L, Havu K, Saarinen K, Bruynzeel DP. Occupational IgE-mediated allergy to Tribolium confusum (confused flour beetle). Allergy. 2000; 55(9):879-82. doi: 10.1034/j.1398-9995.2000.00572.x.

37. Wahrendorf M, Wink M. Pharmacologically active natural products in the defence secretion of Palembus ocularis (Tenebrionidae, Coleoptera). J Ethnopharmacol. 2006; 106(1): 51-6. doi: 10.1016/j. jep.2005.12.007.

38. Skrzypczak-Jankun E, Chorostowska-Wynimko J, Selman SH, Jankun J. Lipoxygenases- A challenging problem in enzyme inhibition and drug development. CurrEnzymInhib. 2007; 3(2):119-132. doi: http://dx.doi.org/10.2174/157340807780598350.

39. Chedea VS, Jisaka M. Inhibition of Soybean Lipoxygenases-Structural and Activity Models for the LipoxygenaseIsoenzymes Family. INTECH Open Access Publisher. 2011. Disponible en: http://cdn. intechweb.org/pdfs/22600.pdf.

40. Kohyama N, Nagata T, Fujimoto S, Sekiya K.Inhibition of arachidonatelipoxygenase activities by 2-(3, 4-dihydroxyphenyl) ethanol, a phenolic compound from olives. BiosciBiotechnolBiochem. 1997; 61(2): 347-50. doi: 10.1271/bbb.61.347.

41. Landa $P$, Kutil Z, Malik J, Kokoska L, Widowitz U, Marsik $P$, Bauer R, Vanek T. In vitro inhibition of 5 -lipoxygenase by natural quinone compounds. Planta Med 2011; 77-102. doi: 10.1055/s-00311282860.

42. Deszcz L, Kozubek A. Inhibition of soybean lipoxygenases by resorcinolic lipids from cereal bran. Cell MolBiolLett. 1997; 2:213-22. Disponible en: http://www.ibmb.uni.wroc.pl/publak/soybean.pdf.

43. Kotsyfakis M, Sá-Nunes A, Francischetti IM, Mather TN, Andersen JF, Ribeiro JM. Antiinflammatory and immunosuppressive activity of sialostatin L, a salivary cystatin from the tick Ixodesscapularis. J Biol Chem. 2006; 281(36):26298-307. doi: 10.1074/jbc.M513010200.

44. Jurenka RA, Howard RW, Blomquist GJ. Prostaglandin synthetase inhibitors in insect defensive secretions. Naturwissenschaften. 1986; 73(12):735-7. doi: 10.1007/BF00399245.

45. Howard R, Jurenka R, Blomquist G. Prostaglandin synthetase inhibitors in the defensive secretion of the red flour beetle Tribolium castaneum (Herbst) (Coleoptera: Tenebrionidae). Insect biochemistry. 1986; 16(5):757-60. doi: 10.1016/0020-1790(86)90111-3.

46. Andersen S. Cuticular sclerotization in the beetles Pachynodae epphipiata and Tenebrio molitor. J Insect Physiol. 1975; 21(6): 1225-32. doi: 10.1016/0022-1910(75)90091-8.

47. Min S, Ryu S, Kim D. Anti-inflammatory effects of black rice, cyanidin-3-O-d-glycoside, and its metabolites, cyanidin and protocatechuic acid. IntImmunopharmacol. 2010; 10(8): 959-66. doi: 10.1016/j.intimp.2010.05.009.

48. Oleg Y, Borbulevych OY, Jankun J, Selman SH, Skrzypczak-Jankun E. Lipoxygenase Interactions With Natural Flavonoid, Quercetin, Reveal a Complex With Protocatechuic Acid in Its X-Ray Structure at 2.1A Resolution. Proteins: StructFunctBioinf. 2004; 54:13-9. doi: 10.1002/prot.10579. 